\title{
What is the effect of noise on the interval timing neural network?
}

\author{
Sorinel A Oprisan ${ }^{1 *}$, Derek Novo ${ }^{1}$, Catalin V Buhusi ${ }^{2}$ \\ From The Twenty Third Annual Computational Neuroscience Meeting: CNS*2014 \\ Québec City, Canada. 26-31 July 2014
}

Cognitive processes, such as decision making, rate calculation and planning, are strongly affected by the ability of subjects to perceive durations in the seconds-tohours range (interval timing) [1]. A classic interval timing paradigm is the peak interval (PI) procedure which consists of interspersed reinforced and probe trials. During the reinforced trials, a stimulus such as a tone or light is turned on to signal the beginning of the to-betimed interval and the subject's first response after the criterion time is reinforced. During the probe trials, no reinforcement is given and the stimulus remains on for about three times the criterion time [2]. The mean response rate over a very large number of trials has a Gaussian shape whose peak measures the accuracy of criterion time estimation and the spread of the timing function measures its precision. In the vast majority of species, protocols, and manipulations to date, interval timing is both accurate and time-scale invariant, i.e. time-estimation errors increase linearly with the estimated duration [3]. We used a computational model of interval timing that mimics the activity of cortico-striatal structures involved in interval timing known as striatal beat frequency (SBF) model (Figure 1) [4]. In mammals, administration of DA agonist, e.g., methamphetamine or cocaine produce an immediate, scalar (proportional), leftward shift in perceived time (responding earlier in time than under control conditions) whereas DA antagonist, e.g., haloperidol, has an opposed effect. Upon
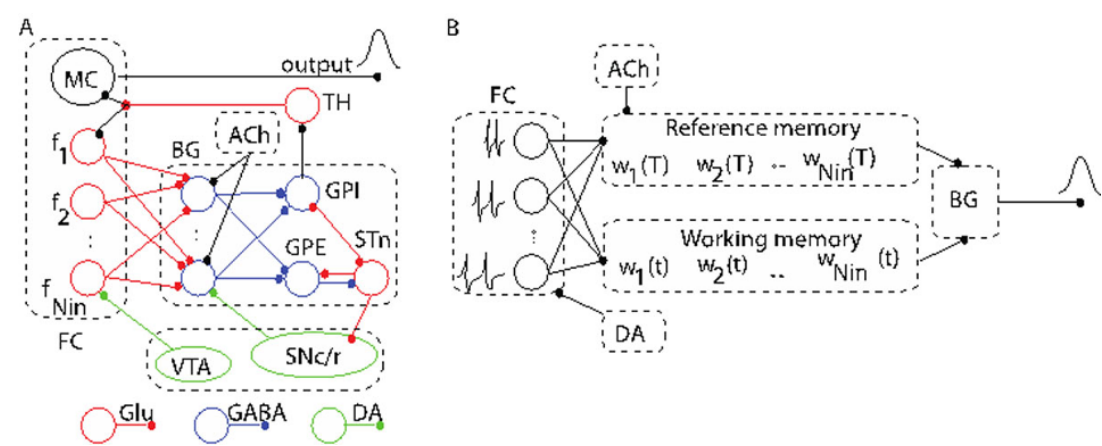

Figure 1 (A) Schematic representation of the two main areas involved in interval timing: frontal cortex (FC) and basal ganglia (BG). (B) SBF model consists of a set of cortical oscillators, a reference memory that stores the state of the system at reinforcement time, a working memory, and a decision block that mimic the activity of BG's spiny neurons. FC: frontal cortex; MC: motor cortex; BG: basal ganglia; TH: thalamus. GPE: globus pallidus external; GPI: globus pallidus internal; STn: subthalamic nucleus; SNc/r: substantia nigra pars compacta/reticulata; VTA: ventral tegmental area; Glu: glutamate; DA: dopamine; GABA: gamma-aminobutyric acid; ACh: acetylcholine.\}

\footnotetext{
* Correspondence: oprisans@cofc.edu

'Department of Physics and Astronomy, College of Charleston, Charleston,

SC 29424, USA

Full list of author information is available at the end of the article
}

() Biomed Central

(c) 2014 Oprisan et al; licensee BioMed Central Ltd. This is an Open Access article distributed under the terms of the Creative Commons Attribution License (http://creativecommons.org/licenses/by/4.0), which permits unrestricted use, distribution, and reproduction in any medium, provided the original work is properly cited. The Creative Commons Public Domain Dedication waiver (http:// creativecommons.org/publicdomain/zero/1.0/) applies to the data made available in this article, unless otherwise stated. 
chronic administration of DA drugs, the timing functions recalibrate, i.e., they shift back to the values prior to drug administration. Once the drug is discontinued, the timing functions rebound (in a scalar manner) in the opposite direction from the initial effects of the drug, which is a signature of the clock pattern. SBF model can mimic clock patterns by adjusting the firing rates of FC neurons proportional to dopamine levels. The frequency modulation by dopaminergic drugs also produces a Gaussian-like output in SBF model. However, behavioral experiments indicate that although the average responses in PI procedure follow an almost Gaussian curve, there is always a notable skewness and a long tail of the output function. We found that frequency variability (noise) determines the deviation form the Gaussian-like output.

\section{Acknowledgements}

This research was supported by the National Science Foundation CAREER award IOS 1054914 to SAO.

\section{Authors' details}

'Department of Physics and Astronomy, College of Charleston, Charleston, SC 29424, USA. ²Department of Psychology, Utah State University, Logan, UT 84322, USA.

Published: 21 July 2014

\section{References}

1. Gallistel CR: The organization of behavior. Cambridge, MA: MIT Press; 1990

2. Catania AC: Reinforcement schedules and psychophysical judgments: $A$ study of some temporal properties of behavior. New York: AppletonCentury-Crofts; 1970

3. Gibbon J: Scalar expectancy theory and Weber's law in animal timing. Psychological Review 1977, 84(3):279-325.

4. Matell MS, Meck WH: Neuropsychological mechanisms of interval timing behavior. Bioessays 2000, 22(1):94-103.

doi:10.1186/1471-2202-15-S1-P74

Cite this article as: Oprisan et al:: What is the effect of noise on the interval timing neural network? BMC Neuroscience 2014 15(Suppl 1):P74.

\section{Submit your next manuscript to BioMed Central} and take full advantage of:

- Convenient online submission

- Thorough peer review

- No space constraints or color figure charges

- Immediate publication on acceptance

- Inclusion in PubMed, CAS, Scopus and Google Scholar

- Research which is freely available for redistribution

Submit your manuscript at www.biomedcentral.com/submit
C Biomed Central 